\title{
A mechanistic-empirical subgrade design model based on Heavy Vehicle Simulator test results
}

\author{
H. L. Theyse ${ }^{1}$, T. P. Hoover ${ }^{2}$, J. T. Harvey ${ }^{3}$, C. L. Monismith ${ }^{4}$ and N. F. Coetzee ${ }^{5}$
}

\begin{abstract}
Although Accelerated Pavement Testing (APT) is often done with specific objectives, valuable pavement performance data is generated over the long-term that may be used to investigate pavement behaviour in general and calibrate mechanisticempirical design models. This paper presents a study on subgrade permanent deformation based on the data generated from a series of Heavy Vehicle Simulator (HVS) tests done at the Richmond Field Station in California. The total subgrade deflection was found to be a better indicator of subgrade permanent deformation than the commonly accepted subgrade vertical strain. A mechanistic-empirical subgrade deformation model was also calibrated successfully for a range of subgrade permanent deformation levels from 1 to $21 \mathrm{~mm}$. The subgrade permanent deformation was found to increase rapidly at subgrade deflection levels above 800 micron.
\end{abstract}

\footnotetext{
${ }^{1}$ Built Environment Unit, CSIR, P.O. Box 395, Pretoria, 0001, South Africa; PH +27-12-841-2269; FAX +27-12-841-2690; email: htheyse @ csir.co.za

2 Caltrans Division of Research and Innovation, Materials and Infrastructure Office, P.O. Box 942873, MS-83 1227 O Street, Sacramento, CA 94273-0001; email: Tom_Hoover@dot.ca.gov

${ }^{3}$ Pavement Research Center, University of California, Davis; Engineering III, Room 3139, One Shields Ave. Davis, CA 95616: PH +1 (530) 754-6409; email: jtharvey@ucdavis.edu

${ }^{4}$ Pavement Research Center, University of California, Berkeley; 1353 S. 46th St, Bldg. 452, Richmond, CA 94804; PH +1 (510)-665-3560; email: clm@ce.berkeley.edu

${ }^{5}$ Dynatest Consulting Inc., 165 S. Chestnut St. Ventura, CA 93001: PH +1 (805) 648-1992; email: nfcoetzee@dynatest.com
} 


\section{Introduction}

Accelerated Pavement Testing (APT) is often done with very specific objectives to test the behaviour and performance of certain pavement components or the pavement as a whole. The "Test Plan for CALHVS1" (Caltrans, 1995) therefore sets out two specific objectives for the initial testing with the Heavy Vehicle Simulator, HVS1 acquired in 1995. These objectives were to evaluate the design methods used for the design of Asphalt Treated Permeable Base (ATPB) layers and conventional Asphalt Concrete (AC) base layers, and to compare the fatigue performance of gap-graded Asphalt Rubber Hot-Mix (ARHM) with that of conventional Dense Graded Asphalt Concrete (DGAC).

These objectives were met by 1999 but in addition to meeting these specific objectives, substantial data on pavement response and performance were generated in the process. Such response and performance data sets may be of great value to calibrate Mechanistic-Empirical (ME) design models, especially now that there is growing international interest in ME pavement design. This paper illustrates how the data from a number of HVS tests that were done at the Richmond Field Station were used to investigate the elastic response and permanent deformation of the subgrade at the field station and to calibrate a permanent deformation design model for this particular subgrade.

\section{HVS test results}

The results from a total of 8 HVS tests were used in the study. The initial four tests were done on two sections with ATPB drainage layers and two sections with conventional aggregate base layers. All of these sections were constructed on a baymud subgrade which is typical of the area. After the initial HVS tests, a $75 \mathrm{~mm}$ DGAC overlay and a $38 \mathrm{~mm}$ ARHM overlay were placed on the original test sections resulting in the combination of base and overlay types shown in Table 1. The HVS was then brought back to test on the exact same locations of the four initial tests. The data collected from these sections form the basis of the study presented in this paper.

Although a number of instruments may be used in association with the HVS, the subgrade study relied almost exclusively on the results from the Multi-Depth Deflectometer. The details of the MDD system have been published elsewhere (de Beer et al, 1988) but essentially this instrument consists of a number of Linear Variable Displacement Transducer modules (LVDTs), installed at predetermined depths in the pavement structure. A core which incorporates the LVDT slugs is anchored at a depth of $3 \mathrm{~m}$ and all measurements are therefore relative to the depth of $3 \mathrm{~m}$. The MDD system allows for both the resilient deflection and permanent deformation of the pavement layers to be recorded. 
Table 1. Pavement structure of the HVS test sections used in the study

\begin{tabular}{cccccc}
\hline HVS & \multicolumn{5}{c}{ Pavement structure design layer thickness (mm) } \\
\cline { 2 - 5 } $\begin{array}{c}\text { Section } \\
\text { no. }\end{array}$ & Overlay & $\begin{array}{c}\text { AC } \\
\text { surfacing }\end{array}$ & $\begin{array}{c}\text { Drainage } \\
\text { layer }\end{array}$ & $\begin{array}{c}\text { Aggregate } \\
\text { base }\end{array}$ & Subbase \\
\hline $500 \mathrm{RF}$ & None & $137 \mathrm{AC}$ & 79 ATPB & 183 & 229 \\
$501 \mathrm{RF}$ & None & $137 \mathrm{AC}$ & None & 274 & 229 \\
$502 \mathrm{RF}$ & None & $137 \mathrm{AC}$ & 79 ATPB & 183 & 229 \\
$503 \mathrm{RF}$ & None & $137 \mathrm{AC}$ & None & 274 & 229 \\
$514 \mathrm{RF}$ & $75 \mathrm{AC}$ & $137 \mathrm{AC}$ & 79 ATPB & 183 & 229 \\
$515 \mathrm{RF}$ & $38 \mathrm{ARHM}$ & $137 \mathrm{AC}$ & None & 183 & 229 \\
$517 \mathrm{RF}$ & $75 \mathrm{AC}$ & $137 \mathrm{AC}$ & 79 ATPB & 274 & 229 \\
$518 \mathrm{RF}$ & $38 \mathrm{ARHM}$ & $137 \mathrm{AC}$ & None & 274 & 229 \\
\hline
\end{tabular}

Figure 1 shows an example of the peak deflection at all the MDD levels recorded at various stages during the HVS test on section 500RF. It is possible to calculate the average vertical strain for each pavement layer from the type of data shown in Figure 1. The difference between the peak deflection recorded by the MDD modules at the top and bottom of a particular layer is divided by the initial offset between the MDD modules to obtain the average strain. In the case of the example shown in Figure 1, the deflections at 625 and $1000 \mathrm{~mm}$ were used to calculate the average vertical strain in the top $375 \mathrm{~mm}$ of the subgrade. In addition to the average vertical strain at the top of the subgrade, the deflection from the MDD module installed at the top of the subgrade also represents the total subgrade deflection.

Figure 2 shows an example of the permanent displacement of the MDD modules with increasing load repetitions. This displacement of the MDD modules is caused by the permanent deformation of the pavement layers with increasing load repetitions. A function of the type $\mathrm{PD}=\mathrm{mN}+\mathrm{a}\left(1-\mathrm{e}^{-\mathrm{bN}}\right)$ (Eq. 1), modified from a function used by Wolff (Wolff, 1992) was fitted to the data from all the MDD levels with high accuracy as illustrated in Figure 2, where PD $(\mathrm{mm})$ is the permanent deformation at a particular MDD level, $\mathrm{N}$ is the number of load repetitions and $\mathrm{a}, \mathrm{b}$ and $\mathrm{m}$ are regression coefficients.

Once the data from the individual HVS test were processed in the manner described above, a data base of number of load repetitions, average vertical strain at the top of the subgrade, total subgrade deflection and subgrade permanent deformation was established. Although the individual HVS tests were done for a range of wheel loads from 40 to $100 \mathrm{kN}$ half-axle loads ( 80 to $200 \mathrm{kN}$ axle loads) by increasing from the lower to the higher wheel load, sufficient data was collected at each wheel load to populate the data base adequately. The load history in terms of the permanent deformation of the pavement was accommodated in the analysis of the data by including the total permanent deformation from a preceding load level into parameter " $a$ " of Equation 1. The data in this data base were used to investigate the permanent deformation of the subgrade and to calibrate ME design models for the subgrade of these HVS tests. 


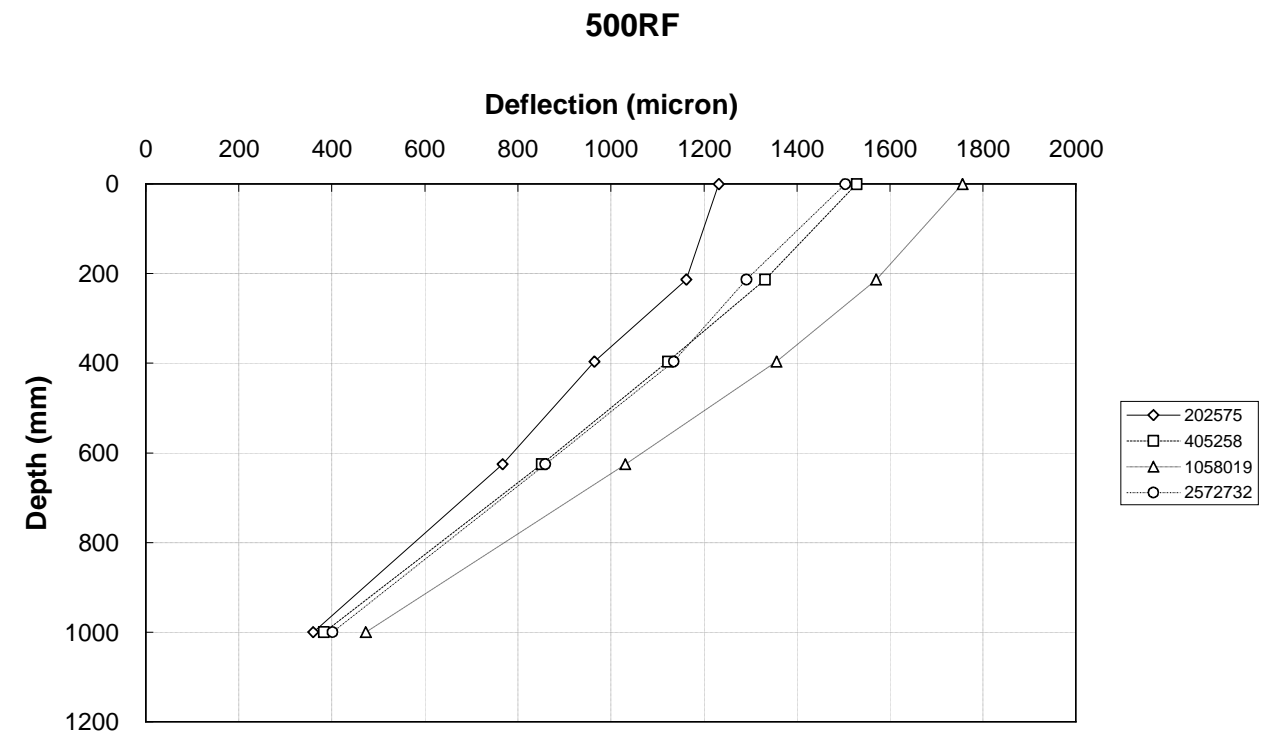

Figure 1. Example of peak MDD deflections at depth in the pavement structure

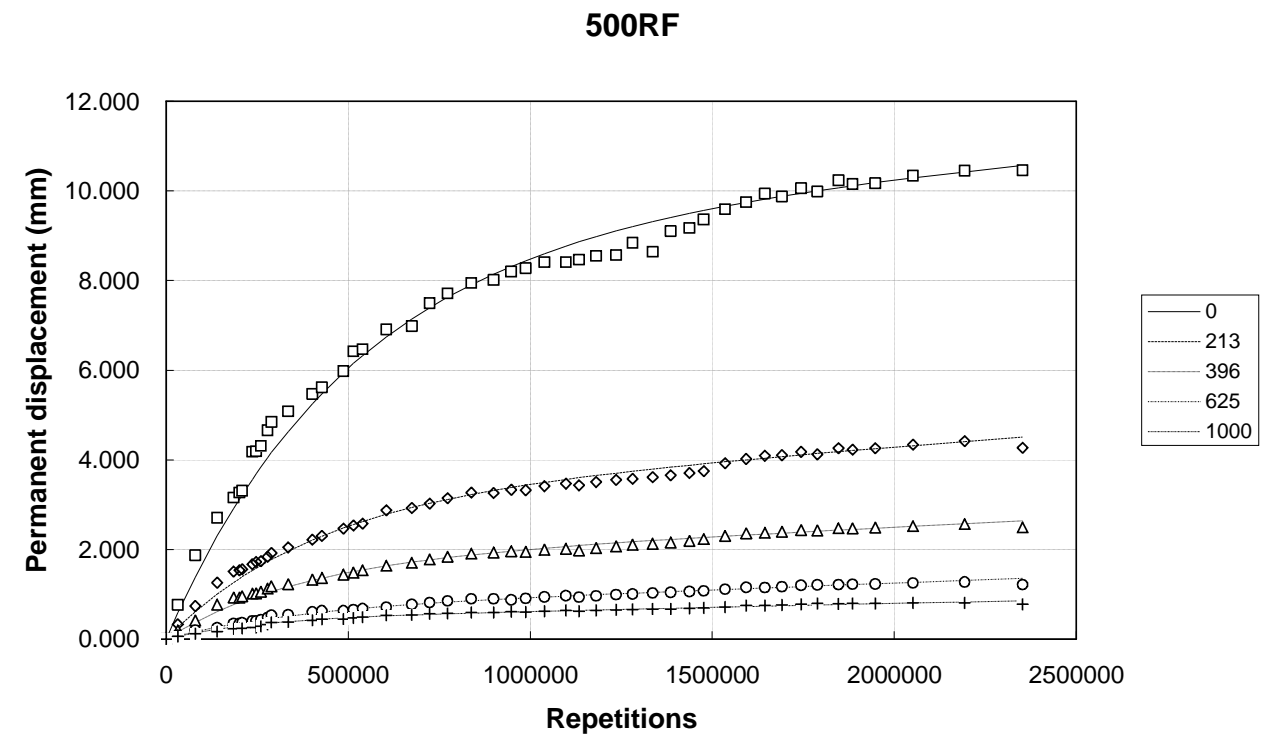

Figure 2. Example of MDD permanent displacement at depth in the pavement structure.

\section{Subgrade design model development}

Selection of an appropriate critical parameter. The vertical strain subgrade design criterion (Dorman and Metcalf, 1965) is well known. Although Dorman and Metcalf never intended the subgrade vertical strain to be used as a predictor of subgrade deformation, this criterion is often applied as such in ME design procedures. The relationship between the initial subgrade vertical strain and subgrade permanent 
deformation was therefore investigated by plotting the subgrade permanent deformation at 1 million load repetitions against the initial subgrade vertical strain as shown in Figure 3.

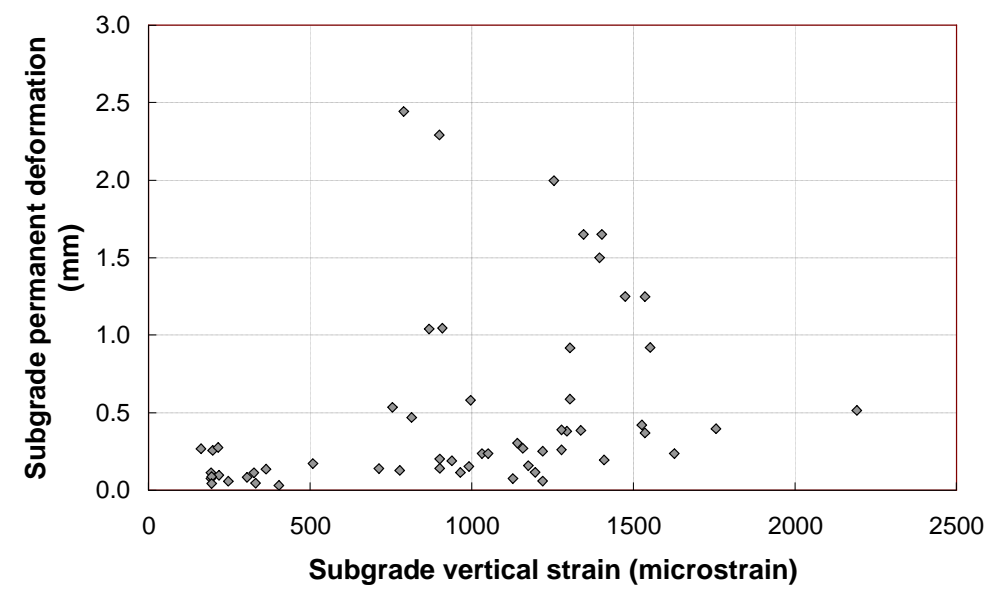

Figure 3. Subgrade permanent deformation at 1 million load repetitions plotted against the initial vertical subgrade strain.

The correlation between subgrade permanent deformation and subgrade vertical strain was unsatisfactory and the process was repeated using the total subgrade deflection measured at each MDD module in the subgrade. The results from this process are shown in Figure 4 and a much better correlation was achieved. The subgrade deflection was therefore selected as the appropriate critical parameter for the design model.



Figure 4. Subgrade permanent deformation at 1 million load repetitions plotted against the initial subgrade deflection.

Design model calibration. The regression model given in Equation 1 was known for the subgrade permanent deformation recorded at each MDD module installed in the subgrade. It was therefore possible to solve for the number of load repetitions $(\mathrm{N})$ required to induce a certain level of subgrade permanent deformation for each MDD 
module installed in the subgrade and to combine this data for all the HVS tests listed in Table 1. The initial subgrade deflection, selected as the critical parameter $(\mathrm{S})$ for the model in the previous section, was also known for each MDD module installed in the subgrade. The relationship between the number of repetitions $(\mathrm{N})$ and the selected critical parameter $(\mathrm{S})$ or subgrade deflection could therefore be investigated. Figure 5 shows an example of an $\mathrm{S}-\mathrm{N}$ plot where the logarithm of the number of repetitions to induce $10 \mathrm{~mm}$ subgrade permanent deformation is plotted against the initial subgrade deflection. A third degree polynomial was fitted to the data using a numerical search routine to minimize the residuals between the model and the data.

$10 \mathrm{~mm}$ Subgrade Deformation Model



Figure 5. Number of repetitions to induce $10 \mathrm{~mm}$ subgrade permanent deformation.

The process described above was repeated for a range of permanent deformation levels from 1 to $21 \mathrm{~mm}$ and a third degree polynomial model fitted to each set of data. The outcome of this process is the subgrade design model shown in Figure 6 and summarised in Table 2. 


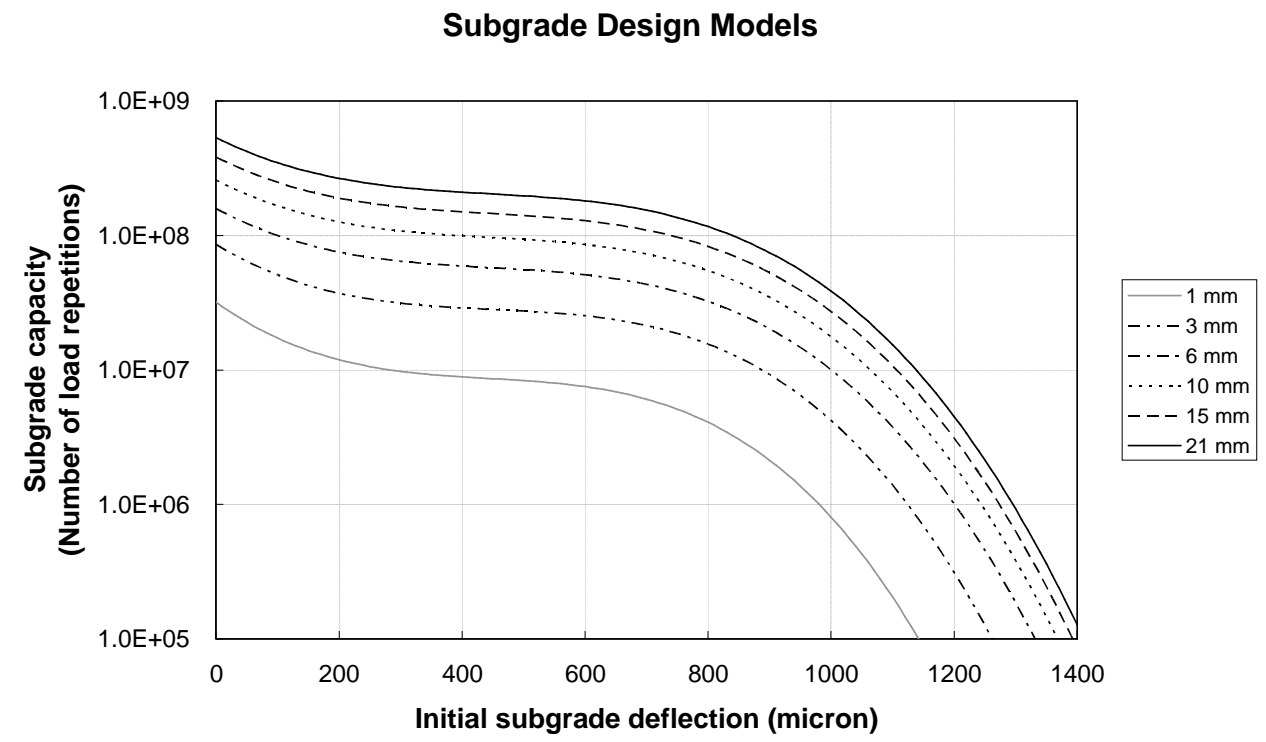

Figure 6. Subgrade design model.

Table 2. Calibration coefficients of the subgrade design model.

\begin{tabular}{ccccccc}
\hline & \multicolumn{3}{c}{ Regression coefficients for $\log (\mathrm{N})$} & \multicolumn{3}{c}{$\begin{array}{c}\text { Regression } \\
\text { parameters }\end{array}$} \\
\hline $\begin{array}{c}\text { Subgrade } \\
\text { deformation }\end{array}$ & Constant & $\begin{array}{c}\text { Linear } \\
\text { term } \\
\left(\times 10^{-3}\right)\end{array}$ & $\begin{array}{c}\text { Quadratic } \\
\text { term } \\
\left(\times 10^{-6}\right)\end{array}$ & $\begin{array}{c}\text { Third } \\
\text { degree } \\
\text { term } \\
\left(\mathrm{x} 10^{-9}\right)\end{array}$ & $\begin{array}{c}\text { SEE for } \\
\log \mathrm{N}\end{array}$ & $\mathrm{R}^{2}$ \\
& & $-3,31$ & 6,86 & $-5,15$ & 0,366 & 0,653 \\
$1 \mathrm{~mm}$ & 7,505 & $-2,79$ & 5,73 & $-4,25$ & 0,324 & 0,609 \\
$3 \mathrm{~mm}$ & 7,933 & $-2,45$ & 4,92 & $-3,67$ & 0,319 & 0,578 \\
$6 \mathrm{~mm}$ & 8,199 & $-2,35$ & 4,69 & $-3,51$ & 0,317 & 0,566 \\
$10 \mathrm{~mm}$ & 8,411 & $-2,35$ & $-3,44$ & 0,317 & 0,561 \\
$15 \mathrm{~mm}$ & 8,583 & $-2,31$ & 4,60 & $-3,46$ & \\
$21 \mathrm{~mm}$ & 8,727 & $-2,29$ & 4,54 & $-3,40$ & 0,316 & 0,558 \\
\hline
\end{tabular}

\section{Conclusions and recommendations}

The results from a number of HVS tests that were done at the Richmond Field Station were used successfully to investigate subgrade permanent deformation and to calibrate a mechanistic-empirical design model for the particular subgrade at the field station.

The subgrade elastic deflection was found to be a better indicator of the subgrade permanent deformation than the vertical strain at the top of the subgrade. This is because the subgrade elastic deflection is representative of the response of the total depth of the subgrade that is influenced by the external load while the vertical strain at the top of the subgrade is only representative of the material conditions and 
response at the top of the subgrade. The subgrade permanent deformation effectively remains constant subgrade deflections below 800 micron but increases rapidly if the initial subgrade deflection exceeds 800 micron.

A mechanistic-empirical subgrade design model was calibrated for different levels of subgrade deformation using the subgrade deflection as the critical parameter controlling subgrade deformation. The model incorporates subgrade deformation data for new and overlaid test sections and satisfactorily accommodated the permanent deformation response of the tests sections after the overlays were placed which could not be done using the subgrade vertical strain as the critical parameter.

The model needs to be extended to include other subgrade types for general application. The application of the design model in a ME design procedure will require that the resilient characteristics of a range of subgrade types are properly quantified in terms of the resilient modulus and stress dependent behaviour as a prerequisite for successful design.

\section{References}

Caltrans (California Department of Transportation) (1995). Test Plan for CALHVS1. Report prepared by Dynatest, Inc., University of California (Berkeley) and CSIR Transportek, http://www.its.berkeley.edu/pavementresearch/ (30 August 2005).

De Beer, M., Horak, E. and Visser, A. T. (1988). "The Multi-Depth Deflectometer (MDD) System for determining the Effective Elastic Moduli of Pavement Layers". ASTM Special Technical Publication, STP 1026, First International Symposium on Non-destructive Testing of Pavements and Back-calculation of Moduli, Baltimore, USA, 1988. pp 70-89.

Dormon G. M. and Metcalf C. T., 1965. "Design curves for flexible pavements based on layered system theory." Highway Research Record, Number 71, Flexible Pavement Design, Highway Research Board, Washington, D. C., 1965, pp. 69-84.

Wolff H. "Elasto-Plastic Behaviour of Granular Pavement Layers in South Africa." Ph D thesis, University of Pretoria, Pretoria, South Africa, 1992. 